Article

\title{
Dutch Cyberbullying Victims’ Experiences, Perceptions, Attitudes and Motivations Related to (Coping with) Cyberbullying: Focus Group Interviews
}

\author{
Niels C.L. Jacobs *, Linda Goossens, Francine Dehue, Trijntje Völlink and Lilian Lechner \\ Faculty of Psychology and Educational Sciences, Open University The Netherlands, Valkenburgerweg \\ 177, PO Box 2960, 6419 AT Heerlen, The Netherlands; E-Mails: lingoossens@gmail.com (L.G.); \\ francien.dehue@ou.nl (F.D.); trijntje.vollink@ou.nl (T.V.); lilian.lechner@ou.nl (L.L.) \\ * Author to whom correspondence should be addressed; E-Mail: niels.jacobs@ou.nl; \\ Tel.: +31-455-76-2874.
}

Academic Editors: Conor Mc Guckin and Lucie Corcoran

Received: 29 October 2014 / Accepted: 6 January 2015 / Published: 13 January 2015

\begin{abstract}
Because of the negative effects of cyberbullying; and because of its unique characteristics; interventions to stop cyberbullying are needed. For this purpose, more insightful information is needed about cyberbullying victims' (i.e., the target group) experiences, perceptions, attitudes and motivations related to (coping with) cyberbullying. Five schools with 66 low-educated Dutch adolescents between 12 and 15 (53\% female) participated in 10 focus group interviews. Results show that victims do not perceive all behaviors as cyberbullying and traditional bullying is generally perceived as worse than cyberbullying. Cyberbullies are perceived as sad, cowards and embarrassing themselves. Victims are perceived as easy targets; they wear strange clothes, act in a provocative manner and have a bad appearance. These perceptions often depend on context, the level of anonymity, being in a fight or not, the person sending the message and his/her behavior. Further, victims reacted to cyberbullying by acting nonchalant, by not actually saying anything and seeking help from others (i.e., parents are not often asked for help because they do not want to bother them; fear of restricted Internet privileges). It can be concluded that asking cyberbullying victims about their experiences in an open manner, and allowing them to discuss these experiences, likely results in new and insightful information compared to using self-reports. In this questioning the perception of adolescents is key to see what is perceived as cyberbullying.
\end{abstract}


Keywords: cyberbullying; adolescents; experiences; attitudes; perceptions; coping strategies; qualitative results

\section{Introduction}

Worldwide, between $20 \%$ and $40 \%$ of adolescents are the victim of cyberbullying [1]. In the Netherlands, this percentage lies around 20\% [2], which is similar to the worldwide prevalence. In addition, the Netherlands appears to have the highest percentage of Internet use among children between 9 and 16 years old [3]. Since heavy Internet use is related to cyberbullying and victimization [4,5], Dutch children have an increased risk of being involved in cyberbullying. Cyberbullying is a repeated aggressive and intentional act, carried out by a group or an individual, using electronic forms of contact. This act is directed towards a victim who cannot easily defend him or herself [6]. Cyberbullying victimization appears to be related to a variety of negative consequences (e.g., anxiety [7], depression, emotional distress [8], suicidality [9,10], school violence and delinquency [11]). Because of the negative consequences, and because of the unique characteristics of cyberbullying (e.g., the bully can stay anonymous and reach a large audience in a relatively short amount of time [12]), some suggest that specific intervention programs are needed [13,14].

Nowadays, there are many anti-bullying websites and programs that are intended for adolescents, their parents and teachers. However, adolescents often do not (want to) talk to adults about their cyberbullying experiences [15-19]. Further, the interventions that currently exist do not specifically target cyberbullying [20], are often based on practical beliefs or commonsense approaches (i.e., without a basis in theory or results of effectiveness [21]), are school-based anti-bullying interventions and/or aim at changing online risk and safety behaviors [22]. Research shows that participation in these interventions is not significantly related to change in Internet risk attitudes or behavior and, in case of the school-based anti-bullying interventions that were researched by Mishna et al. [22], do not affect the number of cyberbullying experiences had by students.

Until now (i.e., to the authors knowledge), there are no specific anti-cyberbullying programs in the Netherlands (see the database of the Netherlands Youth Institute, www.nji.nl). A well-known program, the Finnish school-based anti-bullying program KiVa that is also implemented in the Netherlands, appears to be efficacious in addressing both traditional [23] and cyberbullying [24]. However, the unique effects of KiVa on traditional and cyberbullying are conditional on age (i.e., once students were older than approximately 12.87 years, the effect of the treatment condition was no longer significant), and the effects on cyberbullying and cyber victimization were modest in size [23,24]. Williford et al. [24] therefore suggest that school-based anti-bullying interventions (e.g., KiVa) may need to incorporate additional components that aim specifically at reducing cyberbullying.

Hence, it is important to develop effective and evidence-based anti-cyberbullying interventions, preferably in a planned, systematic and theory-based manner [25]. These interventions should be based on thorough research and recommendations from the literature as well as directly from the target-group, and should: (1) not only increase victims' awareness of possible dangers but also give advice based on what victims need [21]; (2) increase victims' knowledge of effective coping 
strategies [26]; (3) reduce both traditional and cyberbullying because they often occur together [27]; and (4) use personalized information based on unique characteristics of a person [28,29]. Because most of the cyberbullying victims attend lower educational levels (i.e., secondary vocational education as opposed to higher general secondary education and higher academic education) and are transferring to (junior) high school [30,31], an intervention should focus on this specific aged target-group. As mentioned before, $\mathrm{KiVa}$ appears to have no effects in this specific aged target-group. We therefore aim to develop a cyberbullying-specific intervention for Dutch adolescents (12-15 years) who start attending secondary vocational education [32].

To develop an intervention based on the above mentioned recommendations, insight is needed into cyberbullying victims' experiences, perceptions, attitudes and motivations related to (coping with) cyberbullying. It is important to consider these topics in adolescents' own language and words [33]. Focus group interviews could help in gaining more insightful information into what is already known, and to add this information to the current discussion about cyberbullying. A focus group interview is a guided discussion between people who share a number of characteristics. It is an adequate method for obtaining information about the ideas, feelings, attitudes and preferences of a target group. The interaction between participants often results in "in depth" information [34,35]. Focus group interviews are likely to enhance insight into the uniqueness of online experiences and needs of Dutch cyberbullying victims that will help them to combat cyberbullying.

The literature already provides general information about cyberbullying victims' experiences: they are called names, insulted, ignored, misled, hacked, and gossiped about via e-mail and messenger services [2,15,36-39]. They receive pornographic content (i.e., pictures, videos), (their) pictures are forwarded [40] and manipulated, and humiliating websites are created [41]. The most common forms of cyberbullying victimization are name calling and insulting [19] or being contacted by strangers [41]. However, it is not always clear what these experiences constitute and how they take place. Researchers often use self-report questionnaires in which adolescents are not able to give detailed information about their experiences and perceptions concerning cyberbullying. In addition, these questionnaires are developed by researchers, leading to the possibility that some bullying behaviors are overseen, wrongly described, or that some online experiences are wrongly perceived as cyberbullying. It is also unknown whether cyberbullying experiences found in other countries or populations are without exceptions applicable to Dutch cyberbullying victims. Therefore, this study sets out to find more detailed information related to research question (RQ) 1 :

(1) What kind of experiences do Dutch low-educated cyberbullying victims have with cyberbullying victimization and perpetration, and what do they look like?

The (qualitative) literature provides some information about adolescents' perceptions of cyberbullying. Adolescents, for example, perceive repeated, public and anonymous cyberbullying as worse than repeated, public and anonymous traditional bullying [42]. Some adolescents perceive picture and video clip bullying as worse than traditional bullying; email, instant messaging, website and chat room bullying as comparable to traditional bullying; and phone call and text message bullying as less severe than traditional bullying [6,39]. Some negative online behaviors are not considered as cyberbullying but as "another way to bully just over the computer" [37] (p. 1224) or as teasing [2], cyber-teasing or cyber-arguing [41]. Vandebosch and van Cleemput [41] found that adolescents' 
perception of cyberbullying heavily depends on the context in which it takes place, and - in line with the definition of cyberbullying - on the power imbalance and intention to hurt. Although these studies provide important information about adolescents' perceptions, this information is not always conclusive. More information is needed (e.g., for intervention development) that is applicable to the target group, obtained without the use of self-developed and self-report questionnaires. RQ2 therefore is:

(2) How do Dutch low-educated cyberbullying victims perceive/consider experiences with cyberbullying and what is perceived as worse (traditional bullying, cyberbullying, different forms)?

Some studies suggest that a primary motivation for adolescents to cyberbully is anonymity [14,43-46], while for others it is not [19,47]. Apparently, the feeling of anonymity that many online activities entail may contribute to cyberbullying [48]. Other motivations to cyberbully that were found in individual interviews among high-school students (15-19 years) are for example jealousy, rejection, revenge, boredom, to make cyberbullies feel better about themselves, to try out new persona, and to seek approval [47]. Additionally, adolescents mentioned the lack of consequences and confrontation as reasons to cyberbully. Other studies suggest avoiding retaliation or punishment [49] and boy/girlfriend break ups [50] as motivations. Further, according to adolescents, people will become the victim of (traditional) bullying when they have a different appearance, and a bully when they have low self-esteem [51]. However, these sometimes inconclusive results-often found with self-developed self-report questionnaires_are yet to be found among Dutch victims of cyberbullying. RQ3 therefore is:

(3) Why do Dutch low-educated cyberbullying victims think people (cyber) bully (i.e., traditional and cyberbully) each other, who becomes/is a victim and who is a bully?

Research shows that having a positive attitude towards cyberbullying (e.g., cyberbullying is cool, fun, good) is associated with verbal, physical and cyberbullying and negative bystander behavior [14]. One study even found that the attitude towards cyberbullying was the strongest predictor (i.e., compared to subjective norm and perceived behavioral control) of adolescents' intention to cyberbully [52]. Similarly, adolescents who have the tendency to think that aggression is appropriate are more likely to be a cyberbully [53]. Self-reported cyberbullies think that their actions are funny while cyberbully victims perceive their actions as hurtful [54], and those who are less concerned about the possible impact of cyberbullying are more likely to perpetrate in cyberbullying [31]. Although this information can (partly) be used in, for example, intervention development, more information - applicable to Dutch cyberbullying victims - is needed that is obtained without the use of self-developed and self-report questionnaires. RQ4 therefore is:

(4) Which attitudes do Dutch low-educated cyberbullying victims have towards cyberbullying?

Questionnaire-research provides information about adolescents' reactions to cyberbullying. In general, there are two types of ineffective reactions: victims either react passively (i.e., one relinquishes the control of- and reactions to the stressful situation to others, or one lets other areas of life to be adversely affected by the stressful situation [55]) or aggressively (i.e., one reacts to a stressful situation by physically/instrumentally, verbally or emotionally inflicting harm to oneself, another 
person or object). Examples of passive reactions are crying [15], doing nothing or feeling depressed/bad [56]. Examples of aggressive reactions are getting mad/angry or retaliating [2,57,58]. When victims do not react effectively, an incident can quickly and repeatedly reach a large audience [54,59]. There are, however, effective reactions that are considered to be helpful (e.g., confronting the bully [15], seeking social support [6,15,16,60,61] and blocking and deleting the bully $[15,17,19])$. Although many adolescents recommend asking parents for help $[15,61]$, there are also adolescents who do not $[4,16]$. Asking teachers for help is generally not recommended $[15,38]$. Asking peers for help, [15,61] however, and acting in an assertive manner [62] are often recommended and commonly used. Again, it is unknown whether these findings - which are often collected with self-developed self-report questionnaires_are applicable to Dutch cyberbullying victims. RQ5 therefore is:

(5) How do Dutch low-educated cyberbullying victims cope with cyberbullying, and how do they perceive these coping strategies?

\section{Materials and Methods}

\subsection{Recruitment and Participants}

Twenty schools were contacted via e-mail, and were asked to contribute to the discontinuation of cyberbullying by participating in the focus group interviews. The schools were asked to seek for cyberbullying victims (i.e., adolescents who (have) experience(d) cyberbullying), to provide a classroom and time to conduct the interviews. The students were subsequently told that we wanted to talk about their experiences with cyberbullying, and that their information could help us and other adolescents in combating cyberbullying. In total, five schools (response rate: $25 \%$ ) located in the south of the Netherlands (provinces Limburg and Noord-Brabant) with 66 adolescents between 12 and 15 years old, participated in 10 focus group interviews; 53\% was female. All participating students were attending the first class of secondary vocational education.

\subsection{Procedure}

Before the interviews took place, schools received informed consent forms (ICs). Students were instructed to sign the ICs, and to let their parents sign the ICs.

Each focus group consisted of six to eight (former) cyberbullying victims, with one group of four adolescents. In all interviews, two researchers were present: one as interviewer and discussion leader, the other taking notes and checking whether all questions/topics were discussed. The victims were asked permission to record the interview. We explained that no one else but the researchers had access to the recordings, and that they would be used only for research purposes. It was also stressed that all opinions and comments were welcome, and that there were no right or wrong answers. Furthermore, the rules of the focus group interviews were pointed out (e.g., respect each other's opinion, do not talk when someone else is talking). Four interviews were conducted as a pilot test for the intervention, two of them focusing solely on questions from the pilot test. These two interviews were not used in the analysis for this article. 
The interviews lasted between $30 \mathrm{~min}$ and $1.5 \mathrm{~h}(M=59.1 \mathrm{~min}, S D=23.35 \mathrm{~min})$, were semistructured, but all included questions about experiences with-, perceptions of-, coping with- and attitudes about cyberbullying. Research indicates that a direct approach of asking about cyberbullying experiences (e.g., “Did you experience cyberbullying?”) often results in low prevalence figures, because adolescents do not perceive all behaviors as cyberbullying [2,41], and because perception of cyberbullying appears to depend on context [54]. Because perceptions and contexts often differ between persons, we used an indirect approach (e.g., "Which of the following behaviors did you experience?”), in which we did not provide the adolescents with a definition of cyberbullying. This approach allowed us to ask follow-up questions about perceptions and contexts, and enables the adolescents to adjust their answers based on others' opinions.

The questions were printed out on paper prior to the interviews, to facilitate the interviewer and assistant in checking whether all topics were asked, and to allow for similarity in the main questions in each group. To ensure and stimulate discussion about cyberbullying, mostly open-ended questions were used. The main topics and example questions of the interviews are summarized in Table 1 . When all questions were exhaustively answered the victims were thanked for their cooperation, and received some drinks and sweets.

Table 1. Interview schedule with predefined themes.

\begin{tabular}{|c|c|}
\hline Theme & Example Questions \\
\hline \multirow{3}{*}{ Experiencing cyberbullying } & Which of the following cyberbullying events did you experience? \\
\hline & What kind of cyberbullying event did you experience? \\
\hline & What are the consequences of cyberbullying? \\
\hline \multirow{3}{*}{ Performing cyberbullying } & Which of the following cyberbullying events did you perform? \\
\hline & Who cyberbullied someone else? What did you do? \\
\hline & Why did you cyberbully someone else? \\
\hline \multirow{3}{*}{ Perception of cyberbullying } & How do you perceive cyberbullying? \\
\hline & Did you perceive this behavior as cyberbullying? Why? \\
\hline & What do you perceive as worse? Traditional or cyberbullying? Why? \\
\hline \multirow{3}{*}{$\begin{array}{l}\text { Attitude about } \\
\text { cyberbullying }\end{array}$} & What do you think about cyberbullying? \\
\hline & What is worse? Traditional or cyberbullying? \\
\hline & What is the worst thing about cyberbullying? \\
\hline \multirow{3}{*}{ Motives for cyberbullying } & Why do (you think) people cyberbully each other? \\
\hline & Which characteristics does a victim of cyberbullying have? \\
\hline & Which characteristics does a cyberbully have? \\
\hline \multirow{5}{*}{ Coping with cyberbullying } & How do you react to cyberbullying? \\
\hline & How did your cyberbully react to your reaction? \\
\hline & What are other possible reactions towards cyberbullying? \\
\hline & Which reactions do you think are effective in stopping cyberbullying? Why? \\
\hline & Do you talk about experiences with cyberbullying? With whom? Why (not)? \\
\hline
\end{tabular}

\subsection{Data Analysis}

All interviews were recorded and transcribed by the first and second author. In order to become familiar with the data, these two researchers read the transcripts repeatedly. Based on this process, and 
based on the questions asked in the interviews, a coding scheme was developed with main themes and subthemes (see first and second columns of Tables 3-8), using a data-driven thematic approach [63] in which we sought to find insightful information related to the research questions.

Victims talked about traditional bullying as well. Therefore, additional codes for traditional bullying were developed. Moreover, it was not always evident whether victims were talking about traditional or cyberbullying, in which case we refer to (cyber)bullying (i.e., traditional and cyberbullying). The transcripts were subsequently analyzed independently by the first and second author using Qualicoder (www.qualicoder.com). Disagreement in coding was discussed. When no consensus could be reached, the third author was asked for her opinion until consensus was reached. During this process, the coding scheme was adjusted if necessary (i.e., adding more elaborate definitions of categories and codes, adding additional codes). In Table 2, an overview of the (dis)agreements between coders can be found.

Table 2. Agreement and disagreement between coders.

\begin{tabular}{ccccccc}
\hline \multirow{2}{*}{$\begin{array}{c}\text { Focus } \\
\text { group }\end{array}$} & \multicolumn{2}{c}{ Coder 1 } & \multicolumn{2}{c}{ Coder 2 } & & Fragments \\
\cline { 2 - 5 } & $\begin{array}{c}\text { Number of } \\
\text { fragments coded }\end{array}$ & $\begin{array}{c}\text { Disagreement } \\
\text { with coder 2 }\end{array}$ & $\begin{array}{c}\text { Number of } \\
\text { fragments coded }\end{array}$ & $\begin{array}{c}\text { Disagreement } \\
\text { with coder 1 }\end{array}$ & Agreement & $\begin{array}{c}\text { without } \\
\text { Consensus }\end{array}$ \\
\hline Interview 1 & 197 & $74(37,56 \%)$ & 224 & $101(45,09 \%)$ & 123 & 19 \\
Interview 2 & 88 & $20(22,72 \%)$ & 89 & $21(23,60 \%)$ & 68 & 0 \\
Interview 3 & 220 & $31(14,09 \%)$ & 226 & $37(16,37 \%)$ & 189 & 0 \\
Interview 4 & 128 & $19(14,84 \%)$ & 134 & $25(18,66 \%)$ & 109 & 0 \\
Interview 5 & 24 & $6(25 \%)$ & 27 & $11(40,74 \%)$ & 18 & 0 \\
Interview 6 & 41 & $5(12,20 \%)$ & 45 & $9(20 \%)$ & 36 & 0 \\
Interview 7 & 4 & $0(0 \%)$ & 4 & $0(0 \%)$ & 4 & 0 \\
Interview 8 & 18 & $1(5,56 \%)$ & 19 & $3(15,79 \%)$ & 17 & 0 \\
\hline
\end{tabular}

\subsection{Ethics Approval}

The Ethical Commission of the psychology department of the Open University in the Netherlands judged the focus group interviews as non-medical research and concluded that the victims were not "subjected to procedures or required to follow certain rules of behavior" [64]. Therefore, ethical approval of the Regional Medical Ethics committee in the Netherlands was not necessary.

\section{Results}

First, experiences (i.e., victimization and perpetration) with cyberbullying and traditional bullying will be discussed (3.1). Next, victims' perceptions of (cyber)bullying (i.e., what is (not) seen as (cyber)bullying and characteristics of victims and bullies) is discussed (3.2), followed by motivations to cyberbully (3.3), attitudes (3.4), and coping strategies used in response to cyberbullying (3.5)). Although we did not set out to find information about consequences, victims talked about consequences (3.6). Each topic (1-5) has a table with (additional) examples (i.e., Table 3-9). 


\subsection{Experiences with Victimization and Perpetration in (Cyber)bullying}

\subsubsection{What Kind of Experiences do Dutch Low-Educated Cyberbullying Victims Have with} Cyberbullying Victimization in Cyberbullying, and What do They Look Like?

Victims indicated having experienced 16 different forms (see Table 3 "subthemes") of cyberbullying victimization. The most common forms of cyberbullying victimization in several groups were being called names and being ridiculed. Being ignored by someone else and being threatened also occurred quite often, however, more among boys than girls. In four groups, victims experienced that someone-known (e.g., brother) or unknown to them-pretended to be someone else (i.e., impersonation), which made it possible to bully anonymously. In three groups, victims experienced that others lied to them. In five groups, some victims received anonymous e-mails or phone-calls. Less common forms of cyberbullying victimization were, for example, one's picture being placed upon a voting website (two groups), receiving mail bombs (one group), being misled by someone else (one group), breaking into the computer (one group), receiving pornographic content (two groups), and being deleted by someone (one group).

Table 3. Main themes, subthemes and examples for experiences with traditional and cyberbullying.

\begin{tabular}{|c|c|c|}
\hline Final Themes & Subthemes & Examples \\
\hline \multirow{13}{*}{$\begin{array}{l}\text { Experiences } \\
\text { with } \\
\text { cyberbullying }\end{array}$} & Being called names & $\begin{array}{l}\text { Boy: "On the Internet I was playing around on Facebook, and this } \\
\text { girl from my old school started calling me names..." }\end{array}$ \\
\hline & Being ignored & $\begin{array}{l}\text { Girl: “... I was in a fight with someone, I think, and then they } \\
\text { ignored me.” }\end{array}$ \\
\hline & Being deleted & $\begin{array}{l}\text { Girl: “... she deleted me, now she isn’t talking to me anymore, } \\
\text { thank god!” }\end{array}$ \\
\hline & $\begin{array}{l}\text { Being gossiped } \\
\text { about }\end{array}$ & No examples, only raised hands \\
\hline & Being threatened & $\begin{array}{l}\text { Boy: “Once, I received a text message which stated that } \\
\text { someone would enter my room around midnight. However, } \\
\text { it didn’t happen.” }\end{array}$ \\
\hline & Being mislead & No examples, only raised hands \\
\hline & Being lied to & Girl: "Yeah, they just lied to me." \\
\hline & Impersonation & $\begin{array}{l}\text { Boy: “And from someone else, I don't know exactly who it was, } \\
\text { but he sent me messages with four-letter words.” }\end{array}$ \\
\hline & $\begin{array}{l}\text { Being placed upon a } \\
\text { voting website }\end{array}$ & No examples, only raised hands \\
\hline & Being threatened & $\begin{array}{l}\text { Girl: “...I got in a fight with a girl via Hyves* and she was calling } \\
\text { me names and said: 'When I see you, I'll hit you in the face'.” }\end{array}$ \\
\hline & $\begin{array}{l}\text { Uploading unwanted } \\
\text { pictures }\end{array}$ & Girl: “They posted a picture of me on Hyves* while I was sleeping.” \\
\hline & Breaking in & $\begin{array}{l}\text { Boy: "Nothing happened to my computer, but now and again } \\
\text { someone took over the control over my mouse." }\end{array}$ \\
\hline & Changing passwords & $\begin{array}{l}\text { Girl: “On my MSN messenger, I don’t know who it was. I wanted } \\
\text { to log in but it didn’t work anymore.” }\end{array}$ \\
\hline
\end{tabular}


Table 3. Cont.

\begin{tabular}{|c|c|c|}
\hline Final Themes & Subthemes & Examples \\
\hline \multirow{7}{*}{$\begin{array}{l}\text { Experiences } \\
\text { with } \\
\text { traditional } \\
\text { bullying }\end{array}$} & $\begin{array}{l}\text { Receiving mail } \\
\text { bombs }\end{array}$ & $\begin{array}{l}\text { Boy: "Yesterday I checked my Inbox and then there were } \\
493 \text { unread messages about stuff you can buy." }\end{array}$ \\
\hline & $\begin{array}{c}\text { Receiving } \\
\text { pornographic } \\
\text { materials } \\
\end{array}$ & $\begin{array}{l}\text { Boy: "Once I went to Hyves* and someone added me and started } \\
\text { sending me nasty pictures." }\end{array}$ \\
\hline & $\begin{array}{c}\text { Receiving } \\
\text { anonymous } \\
\text { e-mails/phone-calls }\end{array}$ & $\begin{array}{l}\text { Boy: “The past few weeks someone was calling me and then my } \\
\text { phone displays 'Blocked number'. The caller has a thing, a strange } \\
\text { voice. And then I think I know who it is, but then he isn't.” }\end{array}$ \\
\hline & Being called names & Girl: “They call everybody hooker and bitch and so on.” \\
\hline & $\begin{array}{l}\text { Being beaten } \\
\text { up/physical bullying }\end{array}$ & $\begin{array}{l}\text { Boy: "Continuously calling me names, pushing me, stuff like that. } \\
\text { They tried to throw me on the floor, stuff like that. Eight kids } \\
\text { standing around me." }\end{array}$ \\
\hline & Being threatened & Girl: "In this class, some girls came to my house." \\
\hline & Being excluded & $\begin{array}{l}\text { Girl: “They started making noises I didn’t like and started gossiping } \\
\text { about me and counting me out. I really didn’t like that.” }\end{array}$ \\
\hline
\end{tabular}

* Hyves was (until December 2013) a Dutch social networking site.

Inevitably, victims also talked about traditional bullying victimization. Victims from six groups indicated being bullied in a non-specified way. In the same six groups, victims were physically bullied (e.g., kicking, hitting, pushing), and in five groups they were called names. Other, less occurring traditional forms of bullying victimization were being threatened, being excluded and being gossiped about.

\subsubsection{What Kind of Experiences do Dutch Low-Educated Cyberbullying Victims Have with} Cyberbullying Perpetration, and What do They Look Like?

Victims mentioned performing nine specific forms of (cyber)bullying (i.e., it was not always apparent whether they were talking about traditional or cyberbullying, some behaviors occur in both forms of bullying). For instance, in one group, all girls have ridiculed or called someone names. In another group, a girl said: "sometimes as a joke.”. In a third group, a common form of perpetrating in traditional bullying was insulting someone. In the same group, some girls also gossiped about someone. Victims from three groups ignored someone once or twice. Almost all victims from one group also lied to someone. Other, less occurring perpetrations of cyberbullying were threatening someone, changing passwords and uploading unwanted pictures. Additionally, two boys impersonated themselves.

\subsection{How do Dutch Low-Educated Cyberbullying Victims Perceive/Consider Experiences with Cyberbullying and What is Perceived as Worse?}

In five groups, victims mostly talked about what was (not) seen as (cyber)bullying. There was no agreement on, for example, receiving a mail bomb and calling names, since a girl said: "Some people think the word 'loser' is calling names. However, when I call ---- ${ }^{1}$ a loser, she won't get angry. Right 
this morning I called her loser. I don’t think that's bullying.”. However, another girl said: “It depends, when you're in a fight you call each other names and offend each other as well, that doesn't mean that it's bullying. However, when they always do that, and with more people, then I think it is.”. Similarly, there was no agreement on threatening. One girl said: "With threatening, people try to scare you and with bullying this isn't the case. Therefore I think it isn't bullying.” and another girl said "... when you say 'Watch out, tonight at eight o clock I will be standing in front of your house', then I think this is pretty bad.”. Some even consider threatening as being worse than (cyber)bullying. In addition, on being offended no agreement was found. There was agreement on talking negative about family, which victims from different groups always considered as cyberbullying, and lying, which victims do not considered as cyberbullying, even when it is done repeatedly or by an unknown person.

Table 4. Main themes, subthemes and examples for cyberbullying perpetration.

\begin{tabular}{|c|c|c|}
\hline Final Themes & Subthemes & Examples \\
\hline \multirow{9}{*}{$\begin{array}{l}\text { Performing } \\
\text { cyberbullying }\end{array}$} & $\begin{array}{c}\text { Calling } \\
\text { names/ridiculing }\end{array}$ & Girl: "Calling names and ignoring, and ridiculing and stuff...” \\
\hline & Changing passwords & Girl: “On my brother’s phone, just as a joke.” \\
\hline & Gossiping & Girl: "For example gossiping, or directly to the person, just like ----." \\
\hline & Ignoring & No examples, only raised hands \\
\hline & Insulting someone & $\begin{array}{l}\text { Boy: “And, I don’t know how I said it, but I think I said 'It doesn’t } \\
\text { smell so nice over here’ while I was standing next to him. Well, } \\
\text { like 'It smells over here'. It wasn’t really nice.” }\end{array}$ \\
\hline & Lying to someone & No examples, only raised hands \\
\hline & $\begin{array}{l}\text { Misleading/ } \\
\text { impersonation }\end{array}$ & $\begin{array}{l}\text { Boy: "A friend of mine received a text message, and then I send a } \\
\text { message to the sender pretending to be my brother. I told him I was } \\
17 \text { and that I would get to him. He then stopped texting." }\end{array}$ \\
\hline & Threatening & $\begin{array}{l}\text { Boy: “... with a friend, we anonymously send a mail mentioning 'if } \\
\text { you don't stop you'll die'.” }\end{array}$ \\
\hline & $\begin{array}{l}\text { Uploading } \\
\text { unwanted pictures }\end{array}$ & $\begin{array}{l}\text { Girl: "Once I was in a bad fight with a girl, and then I Photo } \\
\text { shopped her head on Lolo Ferrari and posted the picture on Hyves*, } \\
\text { and stuff like that." }\end{array}$ \\
\hline
\end{tabular}

* Hyves was (until December 2013) a Dutch social networking site. ---- Anonymized name.

Table 5. Main themes, subthemes and examples for perceptions of (cyber)bullying.

\begin{tabular}{|c|c|c|}
\hline Final Themes & Subthemes & Examples \\
\hline \multirow{4}{*}{$\begin{array}{l}\text { Perception of } \\
\text { (cyber)bullying }\end{array}$} & $\begin{array}{c}\text { Characteristics of } \\
\text { a victim }\end{array}$ & $\begin{array}{l}\text { Boy: “...they're insecure, but they also often walk alone. And that's } \\
\text { an appearance like, I am just saying, I don't have any friends and } \\
\text { thus I'm kind of bait.” }\end{array}$ \\
\hline & $\begin{array}{c}\text { Characteristics of } \\
\text { a bully }\end{array}$ & $\begin{array}{l}\text { Girl: “Yes everybody can be a bully. Whether it’s someone who’s } \\
\text { very small with glasses and whatever, or someone who’s very tall } \\
\text { and who looks like a bully...”) }\end{array}$ \\
\hline & $\begin{array}{c}\text { Seen as } \\
\text { (cyber)bullying }\end{array}$ & $\begin{array}{l}\text { Boy: “When you just had a fight, and when someone isn’t talking } \\
\text { back to you on Hyves*. I think this is cyberbullying because you try } \\
\text { to make it up and that person perhaps doesn’t even see your } \\
\text { attempts, he just clicks your message away.” }\end{array}$ \\
\hline & $\begin{array}{l}\text { Not seen as } \\
\text { (cyber)bullying }\end{array}$ & $\begin{array}{l}\text { Girl: "Sometimes I think calling names isn’t bullying, sometimes } \\
\text { you do that as friends..." }\end{array}$ \\
\hline
\end{tabular}

* Hyves was (until December 2013) a Dutch social networking site. 
Whether something was seen as (cyber)bullying depended on: (1) the context: for example, repetitiveness, anonymity and the person sending the message were mentioned; (2) the content of the message or photo; and (3) whether the person was willing to delete it (e.g., boys and girls: "It depends on what kind of picture it is and who posted the picture. It also depends on whether that person deletes the picture immediately when you ask for it.”).

\subsection{Why do Dutch Low-Educated Cyberbullying Victims Think People (Cyber)Bully Each Other, Who Becomes/Is a Victim and Who is a Bully?}

Victims mentioned several possible reasons why others are (cyber)bullied; for example, clothing, having a bad appearance, and being an (easy) target (e.g., girl: "People sent out a certain message or ask for it.”). In two groups, victims mentioned that others bully because they are in a bad mood, they want to be popular, they want to feel better about themselves, they are jealous or they act out on someone. Some said that bullies are insecure, while others said they are not. In one group, all victims agreed that everybody can be a bully.

Table 6. Main themes, subthemes and examples for motivations for (cyber)bullying.

\begin{tabular}{ccl}
\hline Final Themes & Subthemes & \multicolumn{1}{c}{ Examples } \\
\hline \multirow{2}{*}{$\begin{array}{c}\text { Motivations to } \\
\text { bully/being bullied }\end{array}$} & $\begin{array}{c}\text { Cyberbullying } \\
\text { victims }\end{array}$ & $\begin{array}{c}\text { Girl: “So provoking others and being lonely, then you're being } \\
\text { an easy target.” }\end{array}$ \\
\cline { 2 - 3 } & $\begin{array}{c}\text { Cyberbullying } \\
\text { bullies }\end{array}$ & Girl: “A bully is insecure at the moment, I think.” \\
\hline
\end{tabular}

\subsection{Which Attitudes do Dutch Low-Educated Cyberbullying Victims have towards Cyberbullying?}

When talking about being (cyber)bullied, a lot of negative attitudes were given (e.g., boy: "No, once I got bullied really bad, and now I know how it feels. It really isn’t funny.”) In several groups, victims considered both traditional and cyberbullying as cowardly. Other opinions about cyberbullies were given in response to someone talking about being cyberbullied (e.g., boy: "Then you're a really sad person.”; and boy: “... I think they embarrass themselves.”). In response to the question whether cyberbullying is worse than traditional bullying, a girl answered: "Yes, I think it is.”. Others thought that traditional bullying was worse. Additionally, when talking about performing bullying, a girl mentioned: “I don’t do that. When I don’t like it myself, I’ll not do it to others.”.

Table 7. Main themes, subthemes and examples of attitudes about (cyber)bullying.

\begin{tabular}{cll}
\hline Final Themes & Subthemes & \multicolumn{1}{c}{ Examples } \\
\hline & Cyberbullying & $\begin{array}{l}\text { Girl: “I think it’s cowardly when you don't have the balls to say } \\
\text { something to me in real life, like 'you're a hooker'. When someone } \\
\text { says that to me via the Internet, than he's a coward.” }\end{array}$ \\
\cline { 2 - 3 } Attitudes & $\begin{array}{c}\text { Specific forms of } \\
\text { (cyber)bullying }\end{array}$ & $\begin{array}{l}\text { Girl: "When the four-letter words aren't that bad I don't mind } \\
\text { that much.” }\end{array}$ \\
\cline { 2 - 3 } & $\begin{array}{c}\text { Cyberbullying } \\
\text { compared to } \\
\text { traditional bullying }\end{array}$ & $\begin{array}{l}\text { Boy: "When they kick you or hit you offline, then I think it's worse } \\
\text { than online." }\end{array}$ \\
\hline
\end{tabular}


3.5. How do Dutch Low-Educated Cyberbullying Victims Cope with Cyberbullying, and How do They Perceive These Coping Strategies?

\subsubsection{Aggressive Coping}

A wide variety of aggressive coping responses were given. In some groups, some of the victims got angry after being cyberbullied. However, the most often used and discussed aggressive coping strategy was retaliation, which was mentioned in four groups (e.g., girl: “...when someone does that (i.e., offending or calling names) to me, yeah then I have the tendency to do the same.”). The most used strategies in response to traditional bullying were fighting back (i.e., getting physical), and retaliating (i.e., calling names), which were mentioned in four groups. Many victims also got angry in response to traditional bullying. Only one girl mentioned that she once agreed to meet for a fight.

\subsubsection{Passive Coping}

In seven groups, the most often discussed passive coping strategy was doing nothing or ignoring the cyberbullying. Another way of doing nothing that was mentioned was sending the word "OK”, as was described by a girl: “One reaction that works really well is sending an ' $\mathrm{O}$ ' and a ' $\mathrm{K}$ '. 'OK' means okay, nobody likes that. Like you aren’t responding.”. Later on she told us: "Yes it’s just on Twitter, when someone calls me a hooker, then I just say 'OK'.”. Another passive coping strategy that was often mentioned in four groups was acting nonchalant or thinking "I don't care”. A third, less often used passive coping strategy was thinking positive or putting things in perspective, which was mentioned in three groups.

\subsubsection{Active Coping}

Victims mentioned several strategies that can be considered as active coping. For example, in four groups, blocking and deleting was mentioned. Other frequently used strategies (i.e., mentioned in five groups) were standing up for oneself, and sometimes the adolescents stood up for someone else. Additionally, victims also mentioned talking about the event. One girl mentioned that seeming self-assured is a good strategy to use, and a boy mentioned: "You could save it in your history, then it will be mentioned in history and then your parents and police will be able to read it.”.

\subsubsection{Seeking Support Coping}

A lot of victims considered seeking social support as a good strategy to use. They mentioned support in general, but also specified their source of support (e.g., parents, teachers, siblings/family, friends). When talking about parents as a source of support, there was a lot of ambiguity. On the one hand, victims told us that they went to their parents and received effective help (e.g., boy: “Then my mother found out and went to my school. Since then they never bullied me again and I don't suffer from it anymore.”) or did not receive help. On the other hand, some victims mentioned that they did not want to bother their parents (e.g., boy: "No, but I'll not tell my parents. It would only be bad for them, because they'll stress out and stuff. While that's not necessary at all, I think.”) or that 
their help would be irritating (e.g., girl: “When you tell your parents they'll react like a parent. That's really annoying!”).

When asked who turns to their friends for help, a boy mentioned: "Yes, I think that everybody does that.”. Otherwise, mostly girls mentioned that they turned to their friends for help. Teachers were mentioned in six groups, however, talking to teachers was not always perceived as useful (e.g., boy: "Occasionally, I went to a teacher, however they hardly did something about it. They only said 'We'll keep an eye out' and even that they didn't do.”). Other sources of support are siblings (i.e., brothers and sisters) or family (i.e., aunts, nephews). Some victims did not seek help. When asked whether they turn to someone for help a girl said: “No, I think it’s my own problem, I can solve it myself.”.

Table 8. Main themes, subthemes and examples of coping with cyberbullying.

\begin{tabular}{|c|c|c|}
\hline Final Themes & Subthemes & Examples \\
\hline \multirow{6}{*}{$\begin{array}{l}\text { Aggressive } \\
\text { coping }\end{array}$} & Getting angry online & $\begin{array}{l}\text { Girl: "It doesn’t make me sad, I just get really angry when people } \\
\text { do stuff like that..." }\end{array}$ \\
\hline & $\begin{array}{l}\text { Retaliating/calling } \\
\text { names online }\end{array}$ & Boy: "When someone does that to me, I do it back, to be honest." \\
\hline & $\begin{array}{l}\text { Agreeing to meet } \\
\text { for a fight offline }\end{array}$ & $\begin{array}{l}\text { Girl: "Very stupid, but then we waylaid for her. We did not really } \\
\text { waylaid for her but agreed to waylay, this sounds really stupid, } \\
\text { however different things happened." }\end{array}$ \\
\hline & $\begin{array}{l}\text { Fighting } \\
\text { back/getting } \\
\text { physical offline }\end{array}$ & $\begin{array}{l}\text { Boy: “Only then he kept doing it. Okay, I wasn’t supposed to do } \\
\text { that, but I grabbed him in his neck, well not lifting him up, and I } \\
\text { pushed him with his head against the door. And then I just reacted } \\
\text { really angry. Anger attack. Because I warned him, but he kept } \\
\text { doing it and kept provoking me.” }\end{array}$ \\
\hline & $\begin{array}{l}\text { Getting angry } \\
\text { offline }\end{array}$ & $\begin{array}{l}\text { Girl: "Getting angry. Then I start yelling, hitting and I grab the } \\
\text { nearest painful object and throw it at their heads." }\end{array}$ \\
\hline & $\begin{array}{l}\text { Retaliating/calling } \\
\text { names offline }\end{array}$ & Boy: "When they call me names, then I do it back three times worse." \\
\hline \multirow{5}{*}{ Active coping } & $\begin{array}{l}\text { Blocking and } \\
\text { deleting }\end{array}$ & $\begin{array}{l}\text { Boy: “Once I was on Hyves* and someone added me and started } \\
\text { sending me nasty pictures. Then I told my mom. After that, } \\
\text { I immediately deleted and blocked him.” }\end{array}$ \\
\hline & Seem self-assured & $\begin{array}{l}\text { Girl: “Loosen up a little bit in class and try to not look insecure. } \\
\text { People will respect you more and they’ll stop bullying you } \\
\text { eventually. That's how it went with me.” }\end{array}$ \\
\hline & $\begin{array}{l}\text { Standing up for } \\
\text { oneself }\end{array}$ & $\begin{array}{l}\text { Boy: "Yeah I once said ‘What you're saying to me, you wouldn’t } \\
\text { like it when I said that to you...”" }\end{array}$ \\
\hline & $\begin{array}{l}\text { Standing up for } \\
\text { someone else }\end{array}$ & $\begin{array}{l}\text { Girl: “Then I completely freaked out on him and told him 'Go and } \\
\text { cry to your mommy'. Because I don't stand it when they do } \\
\text { something like that to my friends. I was really angry!” }\end{array}$ \\
\hline & Talking about it & $\begin{array}{l}\text { Girl: "After a time you just try to talk, because then you both will } \\
\text { be more calm and will be able to talk about it. However, it depends } \\
\text { on what the person said.” }\end{array}$ \\
\hline
\end{tabular}


Table 8. Cont.

\begin{tabular}{|c|c|c|}
\hline Final Themes & Subthemes & Examples \\
\hline \multirow{4}{*}{$\begin{array}{l}\text { Passive } \\
\text { coping }\end{array}$} & $\begin{array}{c}\text { Doing } \\
\text { nothing/ignoring } \\
\text { (the message) }\end{array}$ & $\begin{array}{l}\text { Boy: “Someone, I don’t know who, called me names on Twitter } \\
\text { and then I just let it happen, I didn’t know him so I didn’t reacted } \\
\text { to it.” }\end{array}$ \\
\hline & $\begin{array}{l}\text { Nonchalance/I do } \\
\text { not care }\end{array}$ & $\begin{array}{l}\text { Girl: "When they call me for example a hooker via the Internet, } \\
\text { then I just let that happen. I don’t care. I just know that I am not." }\end{array}$ \\
\hline & Quitting school & $\begin{array}{l}\text { Girl: “...when it happened at my old school, I just thought 'I'll go } \\
\text { to another school'...” }\end{array}$ \\
\hline & $\begin{array}{l}\text { Putting things in } \\
\text { perspective/positive } \\
\text { thinking }\end{array}$ & $\begin{array}{l}\text { Boy: "When they call me names, I always think 'Yeah, you can } \\
\text { call me names, but the only thing you do is making yourself look } \\
\text { smaller and you make a fool out of yourself." }\end{array}$ \\
\hline \multirow{5}{*}{$\begin{array}{l}\text { Seeking } \\
\text { support } \\
\text { coping }\end{array}$} & Friends & Girl: "Most of my friends help me pretty good." \\
\hline & Parents & $\begin{array}{l}\text { Boy: "I just go to my mom, then I tell my mom and dad what's } \\
\text { going on and they tell me what I should do.” }\end{array}$ \\
\hline & Teachers & Girl: "I went to talk to my mentor." \\
\hline & Siblings/family & $\begin{array}{l}\text { Girl: “Once my sister came to this school, they did not dare to } \\
\text { bully me anymore. I wouldn't tell her, but when she hears I'm in } \\
\text { trouble, she immediately comes and helps me.” }\end{array}$ \\
\hline & $\begin{array}{c}\text { Not seeking } \\
\text { support/loneliness }\end{array}$ & $\begin{array}{l}\text { Girl: “Most of the time I don’t talk about it to no one, really no } \\
\text { one. And I keep it to myself.” }\end{array}$ \\
\hline
\end{tabular}

* Hyves was (until December 2013) a Dutch social networking site.

\subsection{Consequences}

Although we did not set out to find information concerning consequences, there were two types of consequences mentioned by the victims. The first type are the consequences of (cyber)bullying victimization. Several victims from different groups mentioned feeling depressed, bad and angry. Some said that the consequences of experiencing (cyber)bullying could last a lifetime (e.g., boy: "Most of the bullies forget the event, but victims experience the consequences for the rest of their lives.”).

The second type were consequences of certain coping strategies in response to cyberbullying. Consequences of getting angry were, for example, fights or the bully going offline. For some, getting angry helped, for others it did not. Additionally, a boy mentioned that ignoring and positive thinking helped. Active coping and seeking support often resulted in the discontinuation of cyberbullying (e.g., girl: 'I just say to them: 'If you want to call me names, come and find me and say it to my face.' Then they stop saying things to me.” or boy: “On the Internet I was just playing around on Facebook and then there was a girl who attended my previous school, and she started calling me names and then I then blocked her and didn’t accept her on my profile.”). After that, the bullying stopped. However, in some cases acting active/effectively did not help (e.g., boy: "Yeah I once said 'What you're saying to me, you wouldn’t like it when I said that to you', however it didn’t help.”). 
Table 9. Main themes, subthemes and examples of consequences of (coping with) (cyber)bullying victimization.

\begin{tabular}{ccl}
\hline Final Themes & Subthemes & \multicolumn{1}{c}{ Examples } \\
\cline { 2 - 3 } Consequences & Victimization & Girl: “A really bad feeling...” \\
\cline { 2 - 3 } & Coping & $\begin{array}{l}\text { Boy: “I became more angry and angry, so eventually there was a big } \\
\text { fight, however since then they don't do anything anymore.” }\end{array}$ \\
\hline
\end{tabular}

\section{Discussion \& Conclusions}

In this study, we aimed to find relevant insightful information into Dutch cyberbullying victims' experiences, perceptions, attitudes and motivations related to (coping with) cyberbullying. We expected that focus group interviews would enable us to get this information. Indeed, this study found new and insightful information that, for example, can be used in intervention development. Before discussing the results, however, a notable finding was made: a lot of victims spontaneously talked about experiences with traditional bullying as well (i.e., physical bullying, being called names, being threatened, and being excluded). This finding can be explained by the large overlap between involvement in traditional and cyberbullying [4,65]: about $40 \%$ of the adolescents who had experienced online harassment did also experienced traditional bullying [66]. Subsequently, cyberbullying is seen as another form of bullying [39,43]. This suggests that interventions should focus on both forms of bullying [27].

In answering RQ1 (i.e., What kind of experiences do Dutch low-educated cyberbullying victims have with cyberbullying victimization and perpetration, and what do they look like?), all participants were victimized but many also perpetrated in cyberbullying (often in response to someone else bullying them). Indeed, the literature shows correlations between victimization and perpetration of cyberbullying [67]. Similar to Juvonen and Gross [19], this study found that being called names and being ridiculed (i.e., insulted) were the most often mentioned victimization behaviors. Besides confirming earlier findings, this study also found new cyberbullying victimization (e.g., being posted upon a voting website, breaking into the computer) and perpetration behaviors (e.g., lying to someone else, changing passwords). It seems that when asking victims about their experiences in an open manner, and allowing them to discuss these experiences, more information is found compared to using self-report questionnaires. Additionally, victims automatically talked about possible consequences (e.g., feeling depressed, bad, angry) of being victimized online. Furthermore, although some research mentions that boys are more often the perpetrators of cyberbullying [2,68], a prominent finding of the present study is that mostly girls perpetrated in the above mentioned behaviors. A possible explanation could be that cyberbullying is in some respects like indirect bullying, in which girls are more often involved [6].

Several studies (e.g., [69,70]) recommend that one should explicitly ask participants about their involvement in specific negative behaviors. In relation to RQ2 (i.e., How do Dutch low-educated cyberbullying victims perceive/consider experiences with cyberbullying and what is perceived as worse?), this study found that victims do not perceive all specific negative behaviors as cyberbullying (i.e., being lied to online, calling names) and thus this approach could give a distorted picture. Apparently, calling names is considered as "normal" communication (i.e., even friends call each other 
names). Victims do not agree with each other on perceiving certain behaviors as cyberbullying (e.g., calling names/being offended, receiving mail bombs, threatening). Victims did perceive-and agreed on-talking negatively about family as cyberbullying. Additionally, being deleted by someone was not completely perceived as negative (i.e., adolescent experienced relief) as was found in [42]. Although some victims perceived cyberbullying as worse than traditional bullying (as was found in [42]), most agreed on traditional bullying being worse than cyberbullying: offline, a message cannot be deleted or ignored, and people can physically hurt you. Furthermore, considering something as cyberbullying in this study indeed depends on the context [4,41] and the level of anonymity [48]. A new finding is that it depends whether the persons involved are in a fight (or not) and on the behavior of the person sending the message (e.g., willing to delete it).

Regarding RQ3 (i.e., Why do Dutch low-educated cyberbullying victims think people (cyber)bully each other, who becomes/is a victim and who is a bully?) this study found motivations to cyberbully reported in previous studies (e.g., jealousy, boredom, to redirect feelings, to feel better, to seek approval, confrontation). Although victims indicated being an occasional victim or bully of cyberbullying, they mostly mentioned motivations why others are being cyberbullied or why others cyberbully, not motivations why they got bullied or why they bully. When talking about motivations, the perspective changes from talking about personal experiences (RQ1) to talking about what others experienced (RQ3). Apparently, victims do not see themselves as cyberbullying victims, but rather as adolescents who once or twice experienced cyberbullying. Similarly, they do not see themselves as cyberbullies but rather as adolescents who occasionally tease someone else, and therefore cannot be called bullies. These findings suggest that the repeated nature, as mentioned in Smith's et al. [6] definition of cyberbullying, really is important in the perception of cyberbullying: single or occasional events are not often perceived as cyberbullying. Future studies should look into which frequency of cyberbullying determines when and if an adolescent perceives something as cyberbullying. In addition, as discussed before, some behaviors are not seen as cyberbullying (e.g., gossiping, calling each other names while being friends), and perception depends on the context and/or being in a fight. In case of these behaviors_contexts and being in a fight—apparently adolescents do not always see themselves as cyberbully or cyberbullying victim. Nevertheless, according to the majority of the participants of this study, everybody can be a cyberbully, and cyberbullies are often insecure. Further, victims mentioned that one's appearance (e.g., easy targets, wear strange clothes, provoke and have a bad appearance) determines becoming a (cyber)bullying victim, which was previously found in traditional bullying [51]. Unfortunately, it was not always clear whether the victims were talking about cyberbullying or only about traditional bullying.

In relation to RQ4 (i.e., Which attitudes do Dutch low-educated cyberbullying victims have towards cyberbullying?), victims provided several negative attitudes (e.g., someone who perpetrates in cyberbullying is sad, a coward and embarrasses him/herself). However, some of these victims also perpetrated (once or twice) in (cyber)bullying, suggesting that having a negative attitude towards (cyber)bullying does not mean that one will not (cyber)bully themselves. A possible explanationfound in response to asking victims about motivations-could be that victims do not perceive themselves as (cyber)bully when they, for example, retaliate or bully occasionally (i.e., once or twice). Further, and new to the literature, some victims disapproved of perpetrating cyberbullying behavior because of reciprocal reasons (e.g., "When I don’t like it myself, I’ll not do it to others.”). 
In exploring RQ5 (i.e., How do Dutch low-educated cyberbullying victims cope with cyberbullying, and how do they perceive these strategies?), this study found aggressive, passive as well as active/effective strategies. The most often mentioned aggressive strategies that were also found in the literature were getting angry [58] — which often resulted in the bully going offline, the message being changed or deleted by the bully, or in a fight-and retaliating [2,71]. The most often mentioned passive strategy that was also found in the literature was doing nothing or ignoring the bully [2], which appeared to be a successful strategy. New to the literature were acting nonchalant and reacting by not actually saying anything (e.g., sending "OK” as a response), which was perceived as helpful.

The most often used active/effective strategies that were also previously found in the literature were blocking and deleting $[15,17,19]$, confronting the bully or standing up for oneself [15], and seeking parents', teachers', siblings/family's and friends' support [6,15,16,60,61]. In general, these strategies are effective in discontinuing bullying, although some adolescents also experienced that the cyberbullying continued. Additionally, victims also stood up for someone else. Further, victims either mentioned talking to adults and receiving effective help (e.g., comfort, parents intervening) or mentioned not wanting to talk to adults because they (as found in the literature): (1) do not want to bother their parents [16]; (2) have the feeling that adults would not be able to help them [72]; (3) have the perception that their friends are more tech-savvy [15]; (4) have experienced that teachers would not react [16]; (5) have the feeling that parents were able to restrict or deny their access to the internet, which could isolate them from their friends and peers [4]; and (6) wanted to solve the problem themselves. Moreover, adolescents mentioned a preference of turning to their friends and other family members (e.g., siblings, nieces/nephews) for support [72].

This study has several strengths and limitations. This study seemed to result into more insightful information than when using a quantitative design. Subsequently, this led to some findings that are not previously reported in the literature. However, this study did not compare qualitative with quantitative designs but merely compared qualitative with quantitative results, suggesting that we cannot conclude that qualitative designs result in more information than quantitative designs. Furthermore, this study is one of the first qualitative studies that included adolescents that had just started to attend lower secondary vocational education. A limitation of this study, on the other hand, is the voluntary cooperation of participants. This may bias the results in that the opinions of victims who do not want/dare to talk about their experiences are overseen. Another limitation is the fact that there were no "pure cyberbullies" included in this study, which may have led to one-sided views. Future research should focus on the views of "pure cyberbullies", because this information might be helpful in reducing cyberbullying as well. Additionally, in this study we did not ask specifically who perceived themselves as a bully or as a victim, and when one perceived themselves as a bully or victim, which may have led to less interpretable results. Future research should also consider these self-perceptions.

In conclusion, the focus group method seems to be promising in finding unstudied concepts related to cyberbullying. It appears that victims perceive traditional and cyberbullying to be related, suggesting that interventions should focus on both forms of bullying. Furthermore, an indirect approach of asking about experiences (e.g., Which of the following behaviors did you experience?) could result in an overestimation of prevalence figures, because victims do not perceive all behaviors as cyberbullying. A direct approach (e.g., How many times were you cyberbullied?) could result in an underestimation of prevalence figure. Therefore, victims should be asked whether they perceive certain 
behaviors as (cyber)bullying, and they should be given a clear definition of cyberbullying, in addition to asking them indirectly about cyberbullying. Further, both boys and girls are victims and perpetrators of cyberbullying, suggesting that interventions should offer a wide variety of information to both boys and girls. Furthermore, an intervention should not communicate that it focuses on victims of cyberbullying, because a lot of adolescents do not perceive themselves as victims. It appears that the focus group method results in at least the same findings as questionnaire research; however, this study also found some new and unstudied concepts. These results can be used in the development of effective interventions with a primary focus on cyberbullying. However, since a lot of overlap exists between traditional and cyberbullying, as suggested by this study, these interventions can have a secondary focus and effect on traditional bullying as well. These results can also directly provide content for a program in a language that members of the target group speak and understand.

\section{Author Contributions}

N.J. and L.G. conceived of the study, recruited participants and drafted the manuscript. N.J. conducted the interviews, T.V. (twice) and L.G. (six times) assisted N.J. in conducting the interviews. N.J. and L.G. independently coded the transcripts, compared the coding and adjusted the coding scheme. F.D. and T.V. served as back-up coders in case of disagreement between N.J. and L.G., F.D. and T.V. helped recruiting participants, helped to draft the manuscript and helped in drafting the final manuscript. L.L. supervised the whole research and helped with drafting and writing the final manuscript. N.J. processed all feedback from the other authors and reviewers. All authors read and approved of the final manuscript.

\section{Conflicts of Interest}

The authors declare no conflict of interest.

\section{References}

1. Tokunaga, R.S. Following you home from school: A critical review and synthesis of research on cyberbullying victimization. Comput. Human Behav. 2010, 26, 277-287, doi:10.1016/j.chb.2009.11.014.

2. Dehue, F.; Bolman, C.; Völlink, T. Cyberbullying: Youngsters' experiences and parental perception. Cyberpsychol. Behav. 2008, 11, 217-223, doi:10.1089/cpb.2007.0008.

3. Livingstone, S.; Haddon, L.; Görzig, A.; Olafsson, K. Risks and Safety on the Internet: The Perspective of European Children: Full Findings and Policy Implications from the EU Kids Online Survey of 9-16 Year Olds and Their Parents in 25 Countries 2011; LSE: London, UK.

4. Kowalski, R.M.; Limber, S.P.; Agatston, P.W. Cyber Bullying: Bullying in the Digital Age; Blackwell Publishing: Malden, MA, USA, 2008.

5. Ybarra, M.L.; Mitchell, K.J. Youth engaging in online harassment: Associations with caregiverchild relationships, Internet use, and personal characteristics. J. Adolesc. 2004, 27, 319-336, doi:10.1016/j.adolescence.2004.03.007. 
6. Smith, P.K.; Mahdavi, J.; Carvalho, M.; Fisher, S.; Russell, S.; Tippett, N. Cyberbullying: Its nature and impact in secondary school pupils. J. Child Psychol. Psychiatry 2008, 49, 376-385, doi:10.1111/j.1469-7610.2007.01846.x.

7. Campbell, M.A.; Spears, B.; Slee, P.; Butler, D.; Kift, S. Victims’ perceptions of traditional and cyberbullying, and the psychosocial correlates of their victimisation. Emot. Behav. Difficulties 2012, 17, 389-401, doi:10.1080/13632752.2012.704316.

8. Perren, S.; Dooley, J.; Shaw, T.; Cross, D. Bullying in school and cyberspace: Associations with depressive symptoms in Swiss and Australian adolescents. Child Adolesc. Psychiatry Ment. Health 2010, 4, 1-10, doi:10.1186/1753-2000-4-28.

9. Hinduja, S.; Patchin, J.W. Bullying, Cyberbullying, and Suicide. Arch. Suicide Res. 2010, 14, 206-221.

10. Schneider, S.K.; O’Donnell, L.; Stueve, A.; Coulter, R.W.S. Cyberbullying, school bullying, and psychological distress: A regional census of high school students. Am. J. Public Health 2012, 102, 171-177, doi:10.2105/AJPH.2011.300308.

11. Hinduja, S.; Patchin, J.W. Offline Consequences of Online Victimization. J. Sch. Violence 2007, 6, 89-112, doi:10.1300/J202v06n03_06.

12. Smith, P.K.; del Barrio, C.; Tokunaga, R.S. Definitions of bullying and cyberbullying: How useful are the terms. In Principles of Cyberbullying Research: Definitions, Measures Methodology; Bauman, S., Cross, D., Walker, J., Eds.; Routledge: London, UK, 2013; pp. 26-45.

13. Kiriakidis, S.P.; Kavoura, A. A Review of the Literature on Harassment Through the Internet and Other Electronic Means. Fam. Community Health 2010, 11, 82-93.

14. Williams, K.R.; Guerra, N.G. Prevalence and Predictors of Internet Bullying. J. Adolesc. Health 2007, 41, S14-S21.

15. Aricak, T.; Siyahhan, S.; Uzunhasanoglu, A.; Saribeyoglu, S.; Ciplak, S.; Yilmaz, N.; Memmedov, C. Cyberbullying among Turkish adolescents. Cyberpsychol. Behav. 2008, 11, 253-261, doi:10.1089/cpb.2007.0016.

16. Hoff, D.L.; Mitchell, S.N. Cyberbullying: Causes, effects, and remedies. J. Educ. Adm. 2009, 47, 652-665, doi:10.1108/09578230910981107.

17. Kowalski, R.M.; Limber, S.P. Electronic Bullying Among Middle School Students. J. Adolesc. Heal. 2007, 41, S22-S30, doi:10.1016/j.jadohealth.2007.08.017.

18. Perren, S.; Corcoran, L.; Cowie, H.; Dehue, F.; Garcia, D.; Mc Guckin, C.; Ševčíková, A.; Tsatsou, P.; Völlink, T. Cyberbullying and traditional bullying in adolescence: Differential roles of moral disengagement, moral emotions, and moral values. Eur. J. Dev. Psychol. 2012, 9, 195-209.

19. Juvonen, J.; Gross, E.F. Extending the school grounds?-Bullying experiences in cyberspace. J. Sch. Health. 2008, 78, 496-505, doi:10.1111/j.1746-1561.2008.00335.x.

20. Slonje, R.; Smith, P.K.; Frisén, A. The nature of cyberbullying, and strategies for prevention. Comput. Human Behav. 2013, 29, 26-32, doi:10.1016/j.chb.2012.05.024.

21. Snakenborg, J.; van Acker, R.; Gable, R.A. Cyberbullying: Prevention and Intervention to Protect Our Children and Youth. Prev. Sch. Fail 2011, 55, 88-95, doi:10.1080/1045988x.2011.539454.

22. Mishna, F.; Cook, C.; Saini, M.; Wu, M.; MacFadden, R. Interventions to Prevent and Reduce Cyber Abuse of Youth: A Systematic Review. Res. Soc. Work Pract. 2011, 21, 5-14, doi:10.1177/1049731509351988. 
23. Kärnä, A.; Voeten, M.; Little, T.D.; Poskiparta, E.; Kaljonen, A.; Salmivalli, C. A Large-Scale Evaluation of the KiVa Antibullying Program: Grades 4-6. Child Dev. 2011, 82, 311-330, doi:10.1111/j.1467-8624.2010.01557.x.

24. Williford, A.; Elledge, L.C.; Boulton, A.J.; dePaolis, K.J.; Little, T.D.; Salmivalli, C. Effects of the KiVa antibullying program on cyberbullying and cybervictimization frequency among Finnish youth. J. Clin. Child Adolesc. Psychol. 2013, 42, 820-833, doi:10.1080/15374416.2013.787623.

25. Bartholomew, L.K.; Parcel, G.S.; Kok, G.; Gottlieb, N.H. Planning Health Promotion Programs: An Intervention Mapping Approach; Jossey-Bass: San Francisco, CA, USA, 2006.

26. Tenenbaum, L.S.; Varjas, K.; Meyers, J.; Parris, L. Coping strategies and perceived effectiveness in fourth through eighth grade victims of bullying. Sch. Psychol. Int. 2011, 32, 263-287, doi:10.1177/0143034311402309.

27. Olweus, D. Invited expert discussion paper Cyberbullying: An overrated phenomenon? Eur. J. Dev. Psychol. 2012, 9, 1-19.

28. Noar, S.M.; Benac, C.N.; Harris, M.S. Does tailoring matter? Meta-analytic review of tailored print health behavior change interventions. Psychol. Bull. 2007, 133, 673-693.

29. Krebs, P.; Prochaska, J.O.; Rossi, J.S. A meta-analysis of computer-tailored interventions for health behavior change. Prev. Med. (Baltim.) 2010, 51, 214-221, doi:10.1016/j.ypmed.2010.06.004.

30. Wade, A.; Beran, T. Cyberbullying: The new era of bullying. Can. J. Sch. Psychol. 2011, 26, 44-61.

31. Walrave, M.; Heirman, W. Cyberbullying: Predicting Victimisation and Perpetration. Child Soc. 2011, 25, 59-72, doi:10.1111/j.1099-0860.2009.00260.x.

32. Jacobs, N.C.; Völlink, T.; Dehue, F.; Lechner, L. Online Pestkoppenstoppen: Systematic and theory-based development of a web-based tailored intervention for adolescent cyberbully victims to combat and prevent cyberbullying. BMC Public Health 2014, 14, 396, doi:10.1186/1471-2458-14-396.

33. Parris, L.; Varjas, K.; Meyers, J.; Cutts, H. High School Students’ Perceptions of Coping with Cyberbullying. Youth Soc. 2011, 44, 284-306, doi:10.1177/0044118X11398881.

34. Kreuger, R.A.; Casey, M.A. Focus Groups. A Practical Guide for Applied Research; Sage Publications: Thoasand Oaks, CA, USA, 2000.

35. Creswell, J.W. Research Design: Qualitative, Quantitative and Mixed Method Approaches; Sage Publications: Thoasand Oaks, CA, USA, 2003.

36. Beran, T.; Li, Q. Cyber-harassment: A study of a new method for an old behavior. J. Educ. Comput. Res. 2005, 32, 265-277, doi:10.2190/8YQM-B04H-PG4D-BLLH.

37. Patchin, J.W.; Hinduja, S. Bullies Move Beyond the Schoolyard: A Preliminary Look at Cyberbullying. Youth Violence Juv. Justice 2006, 4, 148-169, doi:10.1177/1541204006286288.

38. Price, M.; Dalgleish, J. Cyberbullying: Experiences, impacts and coping strategies as described by Australian young people. Youth Stud. Aust. 2010, 29, 51-59.

39. Slonje, R.; Smith, P.K. Cyberbullying: Another main type of bullying? Scand. J. Psychol. 2008, 49, 147-154, doi:10.1111/j.1467-9450.2007.00611.x.

40. Li, Q. New bottle but old wine: A research of cyberbullying in schools. Comput. Human Behav. 2007, 23, 1777-1791, doi:10.1016/j.chb.2005.10.005.

41. Vandebosch, H.; van Cleemput, K. Defining cyberbullying: A qualitative research into the perceptions of youngsters. Cyberpsychol. Behav. 2008, 11, 499-503, doi:10.1089/cpb.2007.0042. 
42. Sticca, F.; Perren, S. Is cyberbullying worse than traditional bullying? Examining the differential roles of medium, publicity, and anonymity for the perceived severity of bullying. J. Youth Adolesc. 2013, 42, 739-750, doi:10.1007/s10964-012-9867-3.

43. Mishna, F.; Saini, M.; Solomon, S. Ongoing and online: Children and youth's perceptions of cyber bullying. Child Youth Serv. Rev. 2009, 31, 1222-1228, doi:10.1016/j.childyouth.2009.05.004.

44. Dehue, F.; Bolman, C.; Völlink, T.; Pouwelse, M. Cyberbullying and traditional bullying in relation with adolescents' perception of parenting. J. CyberTherapy Rehabil. 2012, 5, 25-34.

45. Katzer, C.; Fetchenhauer, D.; Belschak, F. Cyberbullying: Who Are the Victims? J. Media Psychol. Theor. Methods Appl. 2009, 21, 25-36, doi:10.1027/1864-1105.21.1.25.

46. Smith, P.; Mahdavi, J.; Carvalho, M.; Tippett, N. An investigation into cyberbullying, its forms, awareness and impact, and the relationship between age and gender in cyberbullying. Available online: http://webarchive.nationalarchives.gov.uk/20130401151715/http://www.education.gov.uk/ publications/eOrderingDownload/RBX03-06.pdf (accessed on 5 December 2013).

47. Varjas, K.; Talley, J.; Meyers, J.; Parris, L.; Cutts, H. High school students' perceptions of motivations for cyberbullying: An exploratory study. West J. Emerg. Med. 2010, 11, 269-273.

48. Chen, H.-G.; Chen, C.C.; Lo, L.; Yang, S.C. Online privacy control via anonymity and pseudonym: Cross-cultural implications. Behav. Inf. Technol. 2008, 27, 229-242, doi:10.1080/01449290601156817.

49. Compton, L.; Campbell, M.A.; Mergler, A. Teacher, parent and student perceptions of the motives of cyberbullies. Soc. Psychol. Educ. 2014, doi:10.1007/s11218-014-9254-X.

50. Strom, P.; Strom, R.; Walker, J.; Sindel-Arrington, T.; Beckert, T. Adolescent Bullies on Cyber Island. NASSP Bull. 2011, 95, 195-211, doi:10.1177/0192636511418641.

51. Frisen, A.; Jonsson, A.; Persson, C. Adolescents' perception of bullying: Who is the victim? Who is the bully? What can be done to stop bullying? Adolescence 2007, 42, 749-761.

52. Heirman, W.; Walrave, M. Predicting adolescent perpetration in cyberbullying: An application of the theory of planned behavior. Psicothema 2012, 24, 614-620.

53. Calvete, E.; Orue, I.; Estévez, A.; Villardón, L.; Padilla, P. Cyberbullying in adolescents: Modalities and aggressors' profile. Comput. Human Behav. 2010, 26, 1128-1135, doi:10.1016/j.chb.2010.03.017.

54. Vandebosch, H.; van Cleemput, K. Cyberbullying among youngsters: Profiles of bullies and victims. New Media Soc. 2009, 11, 1349-1371, doi:10.1177/1461444809341263.

55. Field, T.; McCabe, P.M.; Schneiderman, N. Stress and Coping; Erlbaum: Hillsdale, NJ, USA, 1985.

56. Völlink, T.; Bolman, C.A.W.; Dehue, F.; Jacobs, N.C.L. Coping with Cyberbullying: Differences Between Victims, Bully-victims and Children not Involved in Bullying. J. Community Appl. Soc. Psychol. 2013, 23, 7-24, doi:10.1002/casp.2142.

57. Monks, C.P.; Robinson, S.; Worlidge, P. The emergence of cyberbullying: A survey of primary school pupils' perceptions and experiences. Sch. Psychol. Int. 2012, 33, 477-491, doi:10.1177/0143034312445242.

58. Ortega, R.; Elipe, P.; Mora-Merchán, J.A.; Genta, M.L.; Brighi, A.; Guarini, A.; Smith, P.K.; Thompson, F.; Tippett, N. The emotional impact of bullying and cyberbullying on victims: A European cross-national study. Aggress Behav. 2012, 38, 342-356, doi:10.1002/ab.21440. 
59. Patchin, J.W.; Hinduja, S. Traditional and Nontraditional Bullying Among Youth: A Test of General Strain Theory. Youth Soc. 2011, 43, 727-751, doi:10.1177/0044118x10366951.

60. Stacey, E. Research into cyberbullying: Student perspectives on cybersafe learning environments. Informatics Educ. 2009, 8, 115-130.

61. Topçu, C.; Erdur-Baker, O.; Capa-Aydin, Y. Examination of cyberbullying experiences among Turkish students from different school types. Cyberpsychol. Behav. 2008, 11, 643-648, doi:10.1089/cpb.2007.0161.

62. Machmutow, K.; Perren, S.; Sticca, F.; Alsaker, F.D. Peer victimisation and depressive symptoms: Can specific coping strategies buffer the negative impact of cybervictimisation? Emot. Behav. Difficulties 2012, 17, 403-420, doi:10.1080/13632752.2012.704310.

63. Braun, V.; Clarke, V. Using thematic analysis in psychology. Qual. Res. Psychol. 2006, 3, 77-101, doi:10.1191/1478088706qp063oa.

64. Centrale Commissie Mensgebonden onderzoek CCMO (Central Committee on Human Research) Available online: http://www.ccmo.nl/en/help-mij-op-weg (accessed on 9 January 2015).

65. Ybarra, M.L.; Diener-West, M.; Leaf, P.J. Examining the Overlap in Internet Harassment and School Bullying: Implications for School Intervention. J. Adolesc. Health 2007, 41, S42-S50, doi:10.1016/j.jadohealth.2007.09.004.

66. Varjas, K.; Henrich, C.C.; Meyers, J. Urban Middle School Students' Perceptions of Bullying, Cyberbullying, and School Safety. J. Sch. Violence 2009, 8, 159-176, doi:10.1080/15388220802074165.

67. Li, Q. Cyberbullying in Schools: A Research of Gender Differences. Sch. Psychol. Int. 2006, 27, 157-170, doi:10.1177/0143034306064547.

68. Hopkins, L.; Taylor, L.; Bowen, E.; Wood, C. A qualitative study investigating adolescents' understanding of aggression, bullying and violence. Child Youth Serv. Rev. 2013, 35, 685-693, doi:10.1016/j.childyouth.2013.01.012.

69. Vaillancourt, T.; McDougall, P.; Hymel, S.; Krygsman, A.; Miller, J.; Stiver, K.; Davis, C. Bullying: Are researchers and children/youth talking about the same thing? Int. J. Behav. Dev. 2008, 32, 486-495, doi:10.1177/0165025408095553.

70. Riebel, J.; Jäger, R.S.; Fischer, U.C. Cyberbullying in Germany-An exploration of prevalence, overlapping with real life bullying and coping strategies. Psychol. Sci. Q. 2009, 51, 298-314.

71. Perren, S.; Corcoran, L.; Cowie, H.; Dehue, F.; Garcia, D.; Mc Guckin, C.; Sevcikova, A.; Tsatsou, P.; Völlink, T. Tackling cyberbullying: Review of empirical evidence regarding successful responses by students, parents, and schools. Int. J. Conf. Violence 2012, 6, 283-292.

72. Hunter, S.C.; Boyle, J.M.E.; Warden, D. Help seeking amongst child and adolescent victims of peer-aggression and bullying: The influence of school-stage, gender, victimisation, appraisal, and emotion. Br. J. Educ. Psychol. 2004, 74, 375-390, doi:10.1348/0007099041552378.

(C) 2015 by the authors; licensee MDPI, Basel, Switzerland. This article is an open access article distributed under the terms and conditions of the Creative Commons Attribution license (http://creativecommons.org/licenses/by/4.0/). 